\title{
Stability of hepatitis C virus (HCV) RNA levels among interferon-naïve HIV/HCV-coinfected individuals treated with combination antiretroviral therapy*
}

D Grint, ${ }^{1}$ L Peters, ${ }^{2}$ J Reekie, ${ }^{1}$ V Soriano, ${ }^{3} 0$ Kirk, ${ }^{2,4}$ B Knysz, ${ }^{5}$ O Suetnov, ${ }^{6}$ A Lazzarin, ${ }^{7}$ B Ledergerber, ${ }^{8}$ JK Rockstroh ${ }^{9}$ and $A$ Mocroft ${ }^{1}$ for EuroSIDA in EuroCoord (European Coordinating Committee for the Integration of Ongoing Coordination Actions Related to Clinical and Epidemiological HIV Research) ${ }^{\dagger}$

${ }^{1}$ University College London, London, UK, ${ }^{2}$ Copenhagen HIV Programme, University of Copenhagen, Copenhagen, Denmark, ${ }^{3}$ Hospital Carlos III, Madrid, Spain, ${ }^{4}$ Department of Infectious Diseases, Rigshospitalet, Copenhagen, Denmark, ${ }^{5}$ Medical University, Wroclaw, Poland, ${ }^{6}$ Regional AIDS Centre, Svetlogorsk, Belarus, ${ }^{7}$ San Raffaele Hospital, Milan, Italy, ${ }^{8}$ Division of Infectious Diseases and Hospital Epidemiology, University Hospital Zurich, University of Zurich, Zurich, Switzerland and ${ }^{9}$ University of Bonn, Bonn, Germany

\section{Objectives}

Infection with hepatitis C virus (HCV) is a major cause of chronic liver disease. High HCV RNA levels have been associated with poor treatment response. This study aimed to examine the natural history of HCV RNA in chronically HCV/HIV-coinfected individuals.

\section{Methods}

Mixed models were used to analyse the natural history of HCV RNA changes over time in HIV-positive patients with chronic HCV infection.

\section{Results}

A total of 1541 individuals, predominantly White (91\%), male (73\%), from southern (35\%) and western central Europe (23\%) and with HCV genotype 1 (58\%), were included in the analysis. The median follow-up time was 5.0 years [interquartile range (IQR) 2.8 to 8.3 years]. Among patients not on combination antiretroviral therapy (cART), HCV RNA levels increased by a mean 27.6\% per year [95\% confidence interval (CI) $6.1-53.5 \% ; P=0.0098$ ]. Among patients receiving CART, HCV RNA levels were stable, increasing by a mean $2.6 \%$ per year (95\% CI -1.1 to $6.5 \%$; $P=0.17)$. Baseline HCV RNA levels were $25.5 \%$ higher (95\% CI 8.8 to $39.1 \% ; P=0.0044)$ in individuals with HCV genotype 1 compared with HCV genotypes 2, 3 and 4. A 1 log HIV-1 RNA copies/mL increase in HIV RNA was associated with a 10.9\% increase (95\% CI 2.3 to 20.2\%; $P=0.012$ ) in HCV RNA.

\section{Conclusions}

While HCV RNA levels increased significantly in patients prior to receiving cART, among those treated with cART HCV RNA levels remained stable over time.

Key words: combination antiretroviral therapy, hepatitis C virus, hepatitis C virus RNA, HIV, viraemia

Accepted 11 February 2013

Correspondence: Mr Daniel Grint, HIV Epidemiology \& Biostatistics Group, Research Department of Infection and Population Health, UCL Royal Free Campus, Rowland Hill Street, London NW3 2PF, UK. Tel: 020 7794 0500, ext. 34684; fax: 0207794 1225; e-mail: d.grint@ucl.ac.uk

*This work was presented in part at the 13th European AIDS Conference (EACS), 12-15 October 2011, Belgrade, Serbia. The work was delivered as an oral presentation under abstract number PS7/3.

tSee Appendix S1 for EuroSIDA study group.

\section{Introduction}

Of the 35 million people currently living with HIV worldwide, approximately 20\% have chronic hepatitis C virus (HCV) infection [1-3]. Coinfection with HCV is one of the most clinically important comorbidities in the HIVinfected population [1-3]. In recent years, mortality rates attributable to HIV infection have decreased as a result of 
antiretroviral therapy [4-6]. As a result, end-stage liver disease has assumed increasing importance as a cause of death among the coinfected population [4-6]. This is especially true for injecting drug users (IDUs), in whom HCV coinfection is common as a result of shared transmission routes $[2,4]$.

Anti-HCV antibody (HCVAb) positivity has been associated with a higher rate of any-cause death and liver-related death [6-10], while plasma HCV RNA, along with HCV genotype and the interleukin (IL)-28B gene variant, has been shown to be one of the most important predictors of sustained virological response (SVR) to pegylated Interferon (peg-IFN) and ribavirin (RBV) in coinfected individuals $[1,4,11-13]$. Furthermore, it has been reported that an HCV RNA measurement taken early after HIV seroconversion can predict progression to AIDS and death in individuals with high HCV viral loads [14]. Although HCV RNA has been reported to stay relatively stable over time in monoinfected individuals $[4,15,16]$, the course of HCV RNA in coinfected individuals is less well characterized $[4,17]$.

The aim of this study was to examine the change over time in HCV RNA levels in HIV/HCV-coinfected individuals to investigate which factors affect baseline levels and the rate of change over time in HCV RNA.

\section{Methods}

\section{Study participants}

The EuroSIDA study is a prospective, observational cohort study of 16594 HIV-positive individuals in 105 centres across Europe, Israel and Argentina. The study has been described in detail previously [18]. In brief, HIV-positive individuals were enrolled into eight cohorts from May 1994 onwards and the median follow-up period of individuals in the cohort is currently to April 2011. Information is collected on a standardized data collection form (available at www.cphiv.dk) every 6 months, including all CD4 T-cell counts and viral loads measured since the last follow-up visit and starting and stopping dates of all antiretroviral (ARV) drugs. The dates of diagnosis of all AIDS-defining illnesses, non-AIDS-defining malignancies and other serious infections are also recorded.

Information on HCVAb status has been collected since 1997; persons who died or were lost to follow-up before this date did not routinely have information on HCVAb status collected. Centres that have determined HCV genotype or measured HCV RNA are requested to provide that information to the coordinating centre. The EuroSIDA plasma repository was set up in 1997 and aims to collect plasma samples from individuals at 6-monthly intervals. Individuals with unknown HCVAb status and a stored plasma sample were identified in 2006 and HCVAb status was determined. Individuals who tested positive for HCVAb were then tested for plasma HCV RNA and genotype in a reference laboratory. In addition, individuals with known HCVAb status but unknown HCV genotype were identified and those with stored samples were also tested for plasma HCV RNA and genotype.

Plasma HCV RNA was investigated and quantified in HCVAb-positive samples by means of the Versant HCV-RNA assay (version 3.0; Bayer Diagnostics, Levekusen, Germany), which uses a signal amplification procedure with a linear dynamic range of 615 to $1 \times 10^{7} \mathrm{IU} / \mathrm{ml}$. Coordinating centres that provide plasma HCV RNA have not previously been required to stipulate which assay was used in determining the HCV RNA level, only to provide the units that it is measured in. Coordinating centres submit HCV RNA data in both copies $/ \mathrm{ml}$ and $\mathrm{IU} / \mathrm{ml}$, but for the purposes of this study we include only data recorded in IU/ml.

HCV genotyping was performed using the LiPA HCV genotype assay (version 2.0; Innogenetics, Gent, Belguim). Information on the assays used to determine plasma HCV RNA and genotype has been previously provided [19].

\section{Statistical analysis}

All HCVAb-positive individuals with positive quantitative HCV RNA measurements, considered chronically infected with HCV, were included in these analyses. HCV RNA measurements taken after individuals had started HCV treatment and those at the upper limit of detection in earlier assays with narrower detection ranges (41 measurements in 39 people) were not included. Baseline in the analysis was defined as the date of the first HCV RNA measurement for each individual. Individuals were followed until their last HCV RNA measurement while HCV treatment naïve. Follow-up was from May 1994 to April 2011; the median date of last HCV RNA measurement prior to treatment for HCV infection was May 2003.

Linear mixed models were used to assess which factors were associated with HCV RNA levels (in $\log _{10} \mathrm{IU} / \mathrm{ml}$ ). Such models allow investigation of whether HCV RNA levels vary at baseline and whether the rate of change over time varies for different factors. Factors considered were: time (from first measurement), age, sex, race, region of Europe, HIV risk/exposure group, HCV genotype, time since first HIVAb positive and the calendar year of the baseline HCV RNA measurement. Hepatitis B virus surface antigen (HBsAg) status, HIV viral load, CD4 cell count and cART status [a protease inhibitor (PI) regimen was defined as containing a PI and at least two other ARVs not including a nonnucleoside reverse transcriptase inhibitor (NNRTI), an NNRTI regimen was defined as containing an NNRTI and at 
least two other ARVs not including a PI, and a more inclusive definition of any cART was at least three ARVs from any class] were included as time updating variables. Time from baseline HCV RNA measurement and the intercept were modelled as random effects. An unstructured covariance structure was used throughout.

Multivariable logistic regression models were used to assess which factors were associated with increases and decreases in HCV RNA levels and which factors were associated with reaching a threshold of $800000 \mathrm{IU} / \mathrm{ml}$, which has been shown to be associated with a poor response to treatment for HCV infection [12].

All analyses were performed using SAS version 9.2 (SAS Institute, Cary, NC).

\section{Results}

There were 14324 patients in EuroSIDA with HCVAb status reported, of whom 4664 were HCVAb positive. Of these,
2670 had HCV RNA data available and 2115 (79.2\%) were chronically infected (HCV RNA positive); 1541 had their HCV RNA data recorded in $\mathrm{IU} / \mathrm{ml}$ with data available on covariates of interest and were eligible for inclusion in this analysis. HCVAb-positive patients without HCV RNA data, who were excluded from this study, were older at the time of their HCVAb-positive test result [odds ratio (OR) 1.37 per 10 years; 95\% confidence interval (CI) 1.201.56; $P<0.0001]$ and were more likely to reside in eastern central or eastern Europe [OR 3.31 (95\% CI 2.29-4.79; $P<0.0001)$ and OR 8.05 (95\% CI 5.45-11.88; $P<0.0001)$ compared with western Europe, respectively] than those with HCV RNA data, who were included in the study.

Baseline characteristics of the 1541 individuals included in the analysis are shown in Table 1 . They were predominantly White (91\%), IDUs (73\%), male (69\%), and from southern (35\%) and western central Europe (23\%); 58\% had HCV genotype 1 while 3, 26 and 14\% had HCV genotypes 2, 3 and 4, respectively. Eighty one per cent were HBsAg

Table 1 Baseline characteristics of 1541 included individuals by combination antiretroviral therapy (cART) status at baseline

\begin{tabular}{|c|c|c|c|c|}
\hline & Total $(n=1541)$ & Off cART $(n=393)$ & On cART $(n=1148)$ & $P$-value \\
\hline \multicolumn{5}{|l|}{ Gender $[n(\%)]$} \\
\hline Male & $1070(69.4)$ & $263(66.9)$ & $807(70.3)$ & \multirow[t]{2}{*}{0.21} \\
\hline Female & $471(30.6)$ & $130(33.1)$ & $341(29.7)$ & \\
\hline \multicolumn{5}{|l|}{$\operatorname{Race}[n(\%)]$} \\
\hline White & $1405(91.2)$ & $365(92.9)$ & $1040(90.6)$ & \multirow[t]{2}{*}{0.17} \\
\hline Nonwhite & $136(8.8)$ & $28(7.1)$ & $108(9.4)$ & \\
\hline Age (years) [median (IOR)] & $37.5(32.1-42.1)$ & $33.9(27.6-39.0)$ & $38.4(33.6-43.0)$ & $<0.0001$ \\
\hline \multicolumn{5}{|l|}{ Region of Europe/country [ $n(\%)]$} \\
\hline Southern & $540(35.0)$ & $111(28.2)$ & $429(37.4)$ & \multirow[t]{6}{*}{$<0.0001$} \\
\hline Western central & $348(22.6)$ & 78 (19.9) & $270(23.5)$ & \\
\hline Northern & $229(14.9)$ & 69 (17.6) & $160(13.9)$ & \\
\hline Eastern central & $246(16.0)$ & $42(10.7)$ & $204(17.8)$ & \\
\hline Eastern & $145(9.4)$ & $89(22.7)$ & $56(4.9)$ & \\
\hline Argentina & $33(2.1)$ & $4(1.0)$ & $29(2.5)$ & \\
\hline \multicolumn{5}{|l|}{ HIV exposure group $[n(\%)]$} \\
\hline MSM & $142(9.2)$ & $21(5.3)$ & $121(10.5)$ & \multirow[t]{5}{*}{0.020} \\
\hline IDU & $1117(72.5)$ & $303(77.1)$ & $814(70.9)$ & \\
\hline Haemophiliac & $49(3.2)$ & $9(2.3)$ & $40(3.5)$ & \\
\hline Heterosexual & $186(12.1)$ & $49(12.5)$ & $137(11.9)$ & \\
\hline Other & $47(3.1)$ & $11(2.8)$ & $36(3.1)$ & \\
\hline \multicolumn{5}{|l|}{ HCV genotype $[n(\%)]$} \\
\hline 1 & $896(58.1)$ & $227(57.8)$ & $669(58.3)$ & \multirow[t]{4}{*}{0.0003} \\
\hline 2 & $39(2.5)$ & $4(1.0)$ & $35(3.1)$ & \\
\hline 3 & $397(25.7)$ & $125(31.8)$ & $272(23.7)$ & \\
\hline 4 & $209(13.6)$ & $37(9.4)$ & $172(15.0)$ & \\
\hline \multicolumn{5}{|l|}{ Baseline HBsAg status $[n(\%)]$} \\
\hline Positive & $95(6.2)$ & $31(7.9)$ & $64(5.6)$ & \multirow[t]{3}{*}{0.012} \\
\hline Negative & $1241(80.5)$ & $325(82.7)$ & $916(79.8)$ & \\
\hline Unknown & 205 (13.3) & $37(9.4)$ & $168(14.6)$ & \\
\hline Baseline CD4 count (cells/ul) [median (IQR)] & $347(200-518)$ & $356(204-510)$ & $340(197-526)$ & 0.12 \\
\hline Baseline HCV RNA ( $\log _{10}$ IU/mI) [median (IQR)] & $5.82(5.31-6.25)$ & $5.78(5.15-6.13)$ & $5.85(5.37-6.30)$ & 0.0019 \\
\hline HIV RNA $<400$ copies/ml $[n(\%)]$ & $702(47.6)$ & $45(11.8)$ & $657(60.1)$ & $<0.0001$ \\
\hline
\end{tabular}

Baseline in this study was defined as the date of the first available HCV RNA measurement. cART was defined as at least three antiretrovirals from any class. $I Q R$, interquartile range; MSM, men who have sex with men; IDU, injecting drug user; $H C V$, hepatitis C virus; $\mathrm{HBsAg}$, hepatitis $B$ virus surface antigen.

${ }^{*} P$-value from $\chi^{2}$ test for comparison of proportions or Kruskal-Wallis test for comparison of population medians. 
negative and 6\% were HBsAg positive, while for 13\% the HBsAg status was unknown. At baseline, those off and on cART differed by age (median 33.9 vs. 38.4 years, respectively; $P<0.0001$ ), region of residence (28.2 vs. $37.4 \%$ in southern Europe, 10.7 vs. 17.8\% in eastern central Europe, and 22.7 vs. 4.9\% in eastern Europe, respectively; global $P<0.0001$ ], HIV transmission group [5.3 vs. 10.5\% men who have sex with men (MSM) and 77.1 vs. 70.9\% IDUs, respectively; global $P=0.02$ ] and HCV genotype (31.8 vs. 23.7\% HCV3 and 9.4 vs. 15.0\% HCV4, respectively; global $P=0.0003)$, while those on cART had a higher proportion of individuals with HIV RNA < 400 copies/ml (11.8\% for those off cART $v$ s. $60.1 \%$ for those on cART; $P<0.0001$ ). The median time from first HIVAb positive was 9.2 years [interquartile range (IQR) 4.8-12.9 years], while the median follow-up time (time from first to last HCV RNA measurement) was 5.0 years (IQR 2.8-8.3 years); 575 individuals had at least two HCV RNA measurements, the median number of measurements per person was 2 (IQR 1-3, range 1-10), and the median time between measurements was 1.7 years (IQR 0.7-4.1 years).

The least squares mean estimates of HCV RNA levels and percentage changes in HCV RNA over time from fitting the mixed model detailed above are shown in Table 2. The 1541 individuals included in this model all contributed to estimates of HCV RNA levels within each stratum; the 575 individuals with at least two HCV RNA measurements contributed to the estimates for the change over time in HCV RNA. Among patients not on cART, HCV RNA levels increased by a mean 27.6\% per year (95\% CI 6.1-53.5\%; $P=0.0098$ ). Among patients taking any form of cART, HCV RNA levels remained stable, increasing by a mean $2.6 \%$ per year (95\% CI -1.1 to $6.5 \% ; P=0.17$ ) but not significantly so. HCV RNA levels also stayed stable among those taking PI-containing and NNRTI-containing regimens [increases of 3.4\% per year (95\% CI -0.2 to $7.2 \%$; $P=0.068)$ and $2.0 \%$ per year $(95 \%$ CI -5.2 to $9.7 \%$; $P=0.59$ ), respectively], with no significant change over time. Figure 1 shows the estimated HCV RNA trajectories for each cART category.

Baseline HCV RNA levels were lower for HCV genotypes 2 to 4 compared with HCV genotype 1 (per cent difference $-25.5 \% ; 95 \% \mathrm{CI}-39.1$ to $-8.8 \% ; P=0.0044)$. There was also some evidence to suggest that baseline HCV RNA levels were lower among those in the haemophiliac HIV transmission group compared with the IDU transmission group (per cent difference $-42.9 \%$; 95\% CI -68.5 to 3.6\%; $P=0.065)$, although this did not reach statistical significance. There was borderline to weak statistical evidence to suggest that HIV RNA levels above the level of detection were associated with higher HCV RNA levels [per cent differences $28.0 \%$ (95\% CI -1.4 to $66.3 \%$; $P=0.064$ ),
$32.4 \%$ (95\% CI -0.8 to $76.7 \% ; P=0.057)$ and $32.5 \%(95 \%$ CI -6.5 to $87.6 \% ; P=0.11$ ) for HIV RNA $400-1000$, $1000-$ 10000 and $>10000$ copies $/ \mathrm{ml}$, respectively, compared with $<400$ copies/ml]. When HIV RNA was fitted as a continuous variable on the $\log _{10}$ scale, it became a significant predictor of HCV RNA, with HCV RNA increasing by $10.9 \%$ per $\log _{10}$ change in HIV RNA (95\% CI 2.3 to 20.2\%; $P=0.012$ ). When age per 10 years and CD4 cell count on the $\log _{2}$ scale were fitted as continuous variables, the associations did not approach statistical significance ( $P=0.31$ and $P=0.81$, respectively).

No interactions between covariates in the mixed model and time were statistically significant except for the cART by time interaction $(P=0.023)$, indicating that the rate of change in HCV RNA over time was only affected by cART in this population.

In a multivariable logistic regression model adjusting for age, HCV genotype, gender, ethnicity, region of Europe, HIV exposure group, HBsAg status, cART initiation status, HIV RNA and CD4 cell count, individuals with an increase in HCV RNA of more than the 90th percentile (a 10\% increase per year) were more likely to have HCV genotype 1 than 2, 3 or 4 [adjusted odds ratio (aOR) 1.37; 95\% CI $1.01-1.86 ; P=0.042]$. In a similar model adjusted for the same factors as above, individuals with a decrease in HCV RNA of more than the 10th percentile (a 7\% decrease per year) were less likely to reside in eastern central or eastern Europe compared with southern Europe [aOR 0.43 (95\% CI $0.22-0.84 ; P=0.013)$ and aOR 0.40 (95\% CI 0.17-0.94; $P=0.035$ ), respectively]. In a similar model adjusted for the same factors, HCV genotype 1 was a significant predictor of reaching a threshold of $800000 \mathrm{IU} / \mathrm{ml}$ in HCV RNA [aOR 1.45 (95\% CI 1.17-1.77; $P=0.0006$ ) compared with genotypes 2, 3 and 4], along with residing in western Europe [aOR 1.71 (95\% CI 1.24-2.34; $P=0.0010$ ) compared with southern Europe].

A number of sensitivity analyses were performed to further examine the increase in HCV RNA levels over time. Including only the 258 individuals with three or more HCV RNA measurements, the increase in HCV RNA over time among patients not on cART was 38.9\% per year (95\% CI 0.7 to $91.8 \% ; P=0.046$ ), while for patients taking any cART HCV RNA was again stable through time, increasing by $1.2 \%$ per year ( $95 \% \mathrm{CI}-4.7$ to $7.4 \% ; P=0.70$ ). Among patients on a PI regimen HCV RNA was stable, with an increase of $3.2 \%$ per year ( $95 \% \mathrm{CI}-3.2$ to $10.1 \% ; P=0.33$ ), while for those on an NNRTI regimen it was also stable, with an increase of $0.2 \%$ per year (95\% CI -33.2 to 56.3\%; $P=0.92$ ).

A further sensitivity analysis including those with three or more HCV RNA measurements, using only data collected from sites and not from stored samples to exclude the 
Table 2 Least squares (LS) estimates of hepatitis C virus (HCV) RNA levels and changes through time

\begin{tabular}{|c|c|c|c|c|c|c|c|}
\hline & \multirow{2}{*}{$\begin{array}{l}\text { LS means at baseline } \\
\left(\log _{10} \mathrm{IU} / \mathrm{ml}\right)\end{array}$} & \multicolumn{3}{|c|}{ Difference within strata at baseline } & \multicolumn{3}{|c|}{ Change in HCV RNA over time } \\
\hline & & $\%$ & $(95 \% \mathrm{Cl})$ & $P$-value ${ }^{+}$ & $\%$ per year & $(95 \% \mathrm{Cl})$ & $P$-value ${ }^{*}$ \\
\hline \multicolumn{8}{|l|}{ cART status } \\
\hline None & 5.50 & 0 & - & - & 27.6 & $(6.1,53.5)$ & 0.0098 \\
\hline All cART & 5.61 & 26.8 & $(-3.0,65.8)$ & 0.083 & 2.6 & $(-1.1,6.5)$ & 0.17 \\
\hline PI regimen & 5.59 & 9.4 & $(-13.4,38.4)$ & 0.45 & 3.4 & $(-0.2,7.2)$ & 0.068 \\
\hline NNRTI regimen & 5.65 & 27.4 & $(-24.0,113.5)$ & 0.35 & 2.0 & $(-5.2,9.7)$ & 0.59 \\
\hline \multicolumn{8}{|l|}{ HCV genotype } \\
\hline 1 & 5.62 & 0 & - & - & & & \\
\hline 2,3 or 4 & 5.49 & -25.5 & $(-39.1,-8.8)$ & 0.0044 & & & \\
\hline \multicolumn{8}{|l|}{ Baseline age } \\
\hline$<30$ years & 5.48 & 0 & - & - & & & \\
\hline $30-40$ years & 5.56 & 20.9 & $(-12.8,67.5)$ & 0.25 & & & \\
\hline $40-50$ years & 5.58 & 27.3 & $(-12.3,84.8)$ & 0.20 & & & \\
\hline$>50$ years & 5.60 & 30.8 & $(-21.0,116.5)$ & 0.30 & & & \\
\hline \multicolumn{8}{|l|}{ Gender } \\
\hline Male & 5.58 & 0 & - & - & & & \\
\hline Female & 5.53 & -11.0 & $(-28.9,11.4)$ & 0.31 & & & \\
\hline \multicolumn{8}{|l|}{ Race } \\
\hline White & 5.53 & 0 & - & - & & & \\
\hline Nonwhite & 5.58 & 10.6 & $(-24.9,62.3)$ & 0.61 & & & \\
\hline \multicolumn{8}{|l|}{ Region of Europe/country } \\
\hline Southern & 5.56 & 0 & - & - & & & \\
\hline Western central & 5.60 & 10.7 & $(-17.1,47.8)$ & 0.49 & & & \\
\hline Northern & 5.59 & 8.4 & $(-21.4,49.7)$ & 0.62 & & & \\
\hline Eastern central & 5.63 & 19.7 & $(-15.0,68.4)$ & 0.31 & & & \\
\hline Eastern & 5.54 & -2.6 & $(-39.5,56.9)$ & 0.92 & & & \\
\hline Argentina & 5.41 & -29.2 & $(-66.3,48.6)$ & 0.36 & & & \\
\hline \multicolumn{8}{|l|}{ HIV transmission group } \\
\hline Injecting drug user & 5.65 & 0 & - & - & & & \\
\hline MSM & 5.52 & -25.3 & $(-48.1,7.4)$ & 0.12 & & & \\
\hline Haemophiliac & 5.41 & -42.9 & $(-68.5 .3 .6)$ & 0.065 & & & \\
\hline Heterosexual & 5.57 & -17.2 & $(-40.0,14.3)$ & 0.25 & & & \\
\hline Other & 5.63 & -3.5 & $(-45.1,69.5)$ & 0.90 & & & \\
\hline \multicolumn{8}{|l|}{ HIV RNA } \\
\hline$<400$ copies $/ \mathrm{ml}$ & 5.47 & 0 & - & - & & & \\
\hline 400-1000 copies/ml & 5.58 & 28.0 & $(-1.4,66.3)$ & 0.064 & & & \\
\hline 1000-10 000 copies $/ \mathrm{ml}$ & 5.59 & 32.4 & $(-0.8,76.7)$ & 0.057 & & & \\
\hline$>10000$ copies $/ \mathrm{ml}$ & 5.59 & 32.5 & $(-6.5,87.6)$ & 0.11 & & & \\
\hline \multicolumn{8}{|l|}{ CD4 count } \\
\hline > 500 cells/ $/ \mu \mathrm{L}$ & 5.54 & 0 & - & - & & & \\
\hline $350-500$ cells $/ \mu \mathrm{L}$ & 5.55 & 2.2 & $(-22.6,35.0)$ & 0.88 & & & \\
\hline $200-350$ cells/ $/ \mu \mathrm{L}$ & 5.54 & -1.1 & $(-23.0,27.2)$ & 0.93 & & & \\
\hline$<200$ cells $/ \mu \mathrm{L}$ & 5.59 & 11.7 & $(-11.7,41.4)$ & 0.36 & & & \\
\hline \multicolumn{8}{|l|}{ HBsAg status } \\
\hline Negative & 5.61 & 0 & - & - & & & \\
\hline Positive & 5.50 & -21.9 & $(-47.9,16.9)$ & 0.23 & & & \\
\hline Unknown & 5.55 & -13.6 & $(-36.9,18.4)$ & 0.36 & & & \\
\hline
\end{tabular}

CART, combination antiretroviral therapy; $\mathrm{Cl}$, confidence interval; MSM, men who have sex with men; NNRTI, nonnucleoside reverse transcriptase inhibitor; $\mathrm{Pl}$, protease inhibitor.

* Least squares mean estimates of HCV RNA levels in each stratum accounting for confounding.

tP-value for comparisons of baseline HCV RNA levels within each stratum.

${ }^{\ddagger}$ P-value for increase through time of HCV RNA compared with null hypothesis of no increase in HCV RNA through time.

possibility that changes in HCV RNA could be explained by degradation over time of stored plasma samples, found that, among patients not on cART, HCV RNA increased by $20.9 \%$ per year $(95 \% \mathrm{CI}-16.9$ to $75.9 \% ; P=0.32)$, although not significantly so as a consequence of the reduced power of this analysis, which included data from 169 patients. In those on any CART, HCV RNA levels again remained stable, with an estimated decrease of 3.1\% per year $(95 \% \mathrm{CI}-11.1$ to $5.6 \% ; P=0.47)$.

\section{Discussion}

This study examined the natural history of plasma HCV RNA in chronically HCV/HIV-coinfected individuals. The 


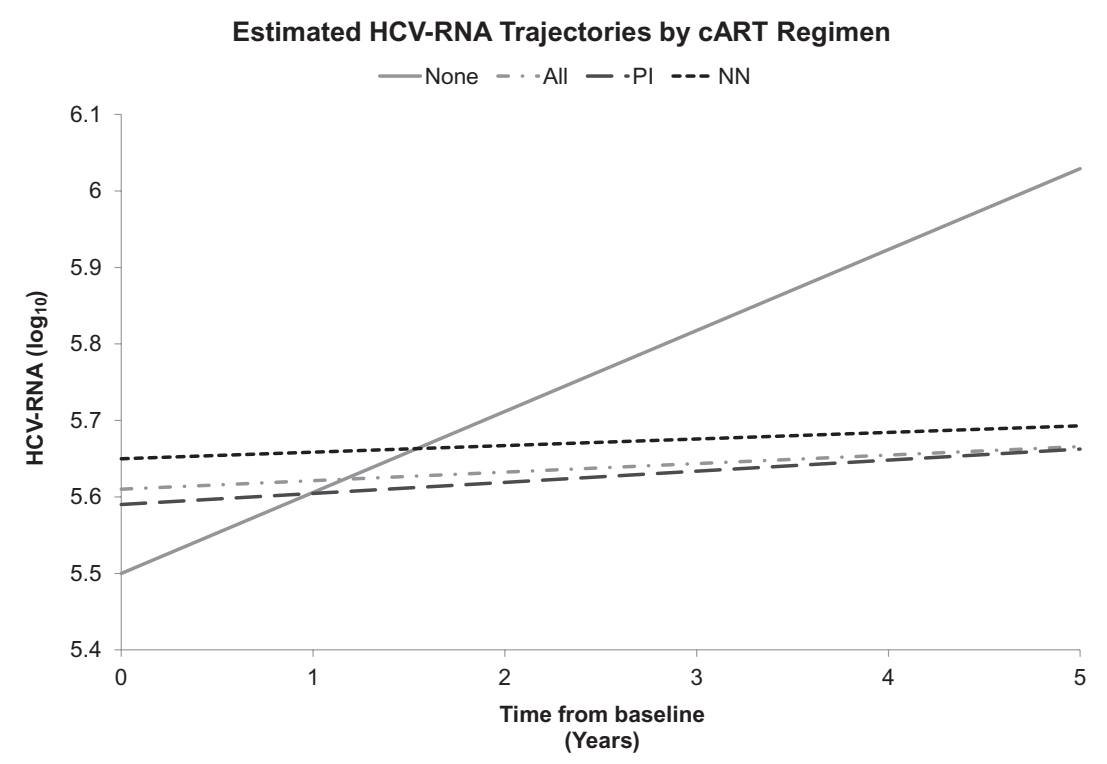

Fig. 1 Estimated hepatitis C virus (HCV) RNA trajectories match the baseline HCV RNA levels and change through time estimated from mixed models. cART, combination antiretroviral therapy; NNRTI, nonnucleoside reverse transcriptase inhibitor; Pl, protease inhibitor.

results show that, among patients not on CART, HCV RNA levels increased over time by $27.6 \%$ per year, compared with a nonsignificant $2.6 \%$ increase per year among patients treated with cART. Further, patients taking a PI-containing regimen had a nonsignificant 3.4\% increase per year, while those taking an NNRTI-containing regimen had a nonsignificant 2.0\% increase per year. This finding adds to the body of work on the topic, such as a study from the USA of coinfected IDUs [4] which found small increases in HCV RNA for coinfected individuals in the region of $2 \%$ per year and increases of $6 \%$ per year in monoinfected individuals; unfortunately, whether patients were treated with CART was not mentioned in this study but our results would suggest that they were. A study in a cohort of coinfected haemophiliacs [17] also showed 8-fold higher increases in HCV RNA among HIV-positive patients compared with HIV-negative patients. One study in a cohort of haemophiliacs in the UK [14] found evidence of an increase in HCV RNA in the first 4 years after HIV seroconversion, after which HCV RNA appeared to stabilize. One benefit of our study is the long duration of follow-up in the cohort; the median time from first HIVAb positive to first HCV RNA measurement was 9.2 (IQR 4.8-12.9) years, meaning we have evidence to suggest that the increase in HCV RNA continues beyond this 4-year period in the absence of treatment for HIV infection, assuming individuals were infected with HCV before or at the same time they became HIV positive. For IDUs, which make up the majority of the study population, this is a reasonable assumption to make because of the shared transmission routes of HIV and HCV, although it is less likely to be the case for MSM and heterosexuals as sexual transmission of HCV is less efficient than that of HIV [20].

While an increase in HCV RNA of $27.6 \%$ per year appears quite striking, we have demonstrated that treatment with cART can stabilize HCV RNA levels in coinfected patients. It is unclear how much influence increasing HCV RNA levels will have on clinician choice when deciding whether to treat for HCV while the association between HCV viral load, disease severity and liver disease remains unclear [16,21]. More weight will often be given to other factors, such as level of fibrosis, HCV genotype, IL-28B gene variant and a patient's readiness for treatment [1,22]. However, with recent studies suggesting a link between high HCV viral loads (> $500000 \mathrm{IU} / \mathrm{ml}$ ) and progression to chronic kidney disease [23,24], increasing HCV RNA could become more clinically important in the future.

HIV viral load when fitted on a $\log _{10}$ continuous scale was found to have a significant relationship with HCV RNA, which further supports our finding that treatment with cART can help to control HCV RNA. These findings, building on evidence from a similar study [4], have potential implications for the treatment of persons with HCV/ HIV coinfection. As lower HIV viral loads predict lower HCV RNA, which is known to be one of the most important predictors of HCV treatment outcome [25], it may be possible to improve the chances of SVR to HCV treatment by controlling HIV viral load and indirectly stabilizing HCV RNA levels in the absence of HCV therapy. However, a short-term transient increase in HCV RNA has been 
reported in coinfected persons initiating cART [26,27], while another study reported that those with low CD4 counts $(<350$ cells $/ \mu \mathrm{L})$ at cART initiation experienced a continuous increase in HCV RNA levels for the 48-week duration of the study [28]. Further, a recent study with a long follow-up period found that there was a small increase in HCV RNA 6 months after cART initiation but a significant decrease in HCV RNA at 70 months after cART initiation [29].

Other studies which have examined the course of HCV RNA levels at 3 and 12 months after the initiation of cART have produced conflicting results [26]. Different studies have found increases and decreases in HCV RNA levels at these time-points following cART initiation, although often the changes were not significant and the results were based on a small number of individuals [30]. It is difficult for us to examine the potential nonlinearity of the course of HCV RNA, attributable to cART initiation, at these time points as $74.5 \%$ of patients were on cART at baseline, with a median time on CART of 2.7 years (IQR 1.0-5.3 years). Interaction terms allowing the rate of change in HCV RNA to differ at 3 and 12 months after cART initiation were excluded from the model as they were nonsignificant (results not shown), meaning we have no evidence to suggest that the linearity of HCV RNA changes over time was affected by cART initiation.

HCV genotype 1 was a significant predictor of higher HCV RNA levels compared with genotypes 2, 3 and 4 . Similarly, some previous studies have shown an association between higher HCV RNA levels and HCV genotype $1[2,4]$, although this has not been seen in others [16,21]; however, these studies have tended to include relatively few individuals, predominantly with HCV genotype 1 . Increases in HCV RNA of more than 10\% per year (the 90th percentile) were also found to be associated with HCV genotype 1, as was reaching a threshold of $800000 \mathrm{IU} / \mathrm{ml}$, which has been reported to be a predictor of a poor response to treatment for HCV [12]. These findings highlight HCV genotype 1 as the most difficult for which to control HCV RNA levels. EuroSIDA has previously published a comparison of baseline HCV RNA levels by genotype [19], but the present study adds important information and considers longitudinal changes in HCV RNA for genotypes 1 to 4 in a relatively large number of individuals.

We found no evidence that HBsAg status influences HCV RNA levels, although baseline HCV RNA levels were lower among HBsAg-positive patients but not significantly so. Many studies have reported that the presence of HBV may favour the clearance of HCV RNA in patients with multiple chronic viral hepatitis infections [19,31,32], including another EuroSIDA study [19]. The fact that HBsAg was not found to be associated with HCV RNA levels in this study could be explained by the low number of HBsAg-positive persons included, 6.2\% at baseline, and the length of time since HCV seroconversion. It is possible that, among the previously multiply coinfected individuals, suppression of HCV had already occurred as a result of the presence of $\mathrm{HBV}$ and that these individuals were HCV RNA negative when testing began.

We found no evidence to suggest that the rate of change in HCV RNA differed by any factors included in the model other than cART. However, we had limited power to detect these differences in the rate of change because of the relatively low number of HCV RNA measurements per person. Further studies are required to fully understand the rate of change in HCV RNA levels and how it may differ according to genotype or other factors, something that could be revisited in time when more data are collected.

Our study has several limitations; most significantly, there were relatively few individuals in our cohort with multiple HCV RNA measurements. Of the 1541 individuals included in the analysis, 258 had three or more HCV RNA determinations. In a sensitivity analysis including only these individuals, HCV RNA increased by 38.9\% per year in patients not on cART and was stable, with an increase of $1.2 \%$ per year, among those taking any cART. A further sensitivity analysis including data from individuals with three or more HCV RNA measurements using data collected from sites only, excluding data from stored samples to discount the possible effect of degradation of HCV RNA in stored samples, produced similar results, a 20.7\% increase in HCV RNA among those not on cART and a 3.1\% decrease among those taking cART, although with reduced statistical significance because of the relatively small number of patients included.

In conclusion, this study demonstrated that, while HCV RNA levels increased during long-term follow-up in coinfected patients not taking cART, among those who had initiated cART HCV RNA levels were stable over time, suggesting that earlier treatment with cART could help to control HCV RNA levels.

\section{Acknowledgements}

Conflicts of interest: $0 \mathrm{~K}$ has received honorarium, consultancy and/or lecture fees from Abbot, Gilead, Janssen, Merck and Viiv. Jürgen Rockstroh has received consultancy or lecture fees from Bionor, BMS, BI, GSK, ViiV, Abbott, Gilead, Pfizer, Merck, Tibotec and Janssen. AM has received honorarium, consultancy or guest speaker fees from Pfizer, Merck, Gilead, BI and BMS. All other authors have no conflicts of interest to report.

Funding: Primary support for EuroSIDA is provided by the European Commission BIOMED 1 (CT94-1637), 
BIOMED 2 (CT97-2713), 5th Framework (QLK2-200000773), 6th Framework (LSHP-CT-2006-018632) and 7th Framework (FP7/2007-2013, EuroCoord no. 260694) programmes. Current support also includes unrestricted grants from Gilead, Pfizer, BMS, and Merck and Co. The participation of centres in Switzerland was supported by The Swiss National Science Foundation (grant 108787).

\section{References}

1 Soriano V, Puoti M, Sulkowski M et al. Care of patients coinfected with HIV and hepatitis C virus: 2007 updated recommendations from the HCV-HIV International Panel. Aids 2007; 21: 73-89.

2 Soriano V, Vispo E, Labarga P, Medrano J, Barreiro P. Viral hepatitis and HIV co-infection. Antiviral Res 2010; 85: 3-15.

3 Eyster ME, Diamondstone LS, Lien JM, Ehmann WC, Quan S, Goedert JJ. Natural-history of hepatitis-C virus-infection in multitransfused hemophiliacs - effect of coinfection with human-immunodeficiency-virus. J Acquir Immune Defic Syndr Hum Retrovirol 1993; 6: 2-10.

4 Fishbein DA, Lo YT, Netski D, Thomas DL, Klein RS. Predictors of hepatitis C virus RNA levels in a prospective cohort study of drug users. Jaids J Acquir Immune Defic Syndr 2006; 41: 71-76.

5 Lesens 0, Deschenes M, Steben M, Belanger G, Tsoukas CM. Hepatitis $\mathrm{C}$ virus is related to progressive liver disease in human immunodeficiency virus-positive hemophiliacs and should be treated as an opportunistic infection. $J$ Infect Dis 1999; 179: 254-258.

6 Rockstroh JK, Mocroft A, Soriano V et al. Influence of hepatitis $\mathrm{C}$ virus infection on HIV-1 disease progression and response to highly active antiretroviral therapy. $J$ Infect Dis 2005; 192: 92-1002.

7 Bonacini M, Louie S, Bzowej N, Wohl AR. Survival in patients with HIV infection and viral hepatitis B or C: a cohort study. Aids 2004; 18: 39-45.

8 Mocroft A, Soriano V, Rockstroh J et al. Is there evidence for an increase in the death rate from liver-related disease in patients with HIV? Aids 2005; 19: 117-125.

9 Weber R. Liver-related deaths in persons infected with the human immunodeficiency virus - The D : A : D study. Arch Intern Med 2006; 166: 632-641.

10 Weis N, Lindhardt B0, Kronborg G et al. Impact of hepatitis $\mathrm{C}$ virus coinfection on response to highly active antiretroviral therapy and outcome in HIV-infected individuals: a Nationwide Cohort Study. Clin Infect Dis 2006; 42: 481-487.

11 Soriano V, Garcia-Samaniego J, Rodriguez-Rosado R, Gonzalez J, Pedreira J. Hepatitis C and HIV infection: biological, clinical, and therapeutic implications. J Hepatol 1999; 31: 119-123.
12 Torriani FJ, Rodriguez-Torres M, Rockstroh JK et al. Peginterferon alfa-2a plus ribavirin for chronic hepatitis C virus infection in HIV-infected patients. N Engl J Med 2004; 351: 38-50.

13 McCarthy JJ, Li JH, Thompson A et al. Replicated association between an IL28B gene variant and a sustained response to pegylated interferon and ribavirin. Gastroenterology 2010; 138: 307-314.

14 Herrero-Martinez E, Sabin CA, Evans JG, Griffioen A, Lee CA, Emery VC. The prognostic value of a single hepatitis $C$ virus RNA load measurement taken early after human immunodeficiency virus seroconversion. J Infect Dis 2002; 186: 70-76.

15 Thomas DL, Astemborski J, Vlahov D et al. Determinants of the quantity of hepatitis C virus RNA. J Infect Dis 2000; 181: 44-51.

16 Yeo AET, Ghany M, Conry-Cantilena C et al. Stability of HCV-RNA level and its lack of correlation with disease severity in asymptomatic chronic hepatitis $\mathrm{C}$ virus carriers. J Viral Hepat 2001; 8: 56-63.

17 Eyster ME, Fried MW, Dibisceglie AM, Goedert JJ. Increasing hepatitis-C virus-rna levels in hemophiliacs - relationship to human-immunodeficiency-virus infection and liver-disease. Blood 1994; 84: 020-023.

18 Mocroft A, Ledergerber B, Katlama C et al. Decline in the AIDS and death rates in the EuroSIDA study: an observational study. Lancet 2003; 362: 2-9.

19 Soriano V, Mocroft A, Rockstroh J et al. Spontaneous viral clearance, viral load, and genotype distribution of hepatitis $\mathrm{C}$ virus (HCV) in HIV-infected patients with anti-HCV antibodies in Europe. J Infect Dis 2008; 198: 337-344.

20 Tohme RA, Holmberg SD. Is sexual contact a major mode of hepatitis C Virus transmission? Hepatology 2010; 52: 497-505.

21 Hollingsworth RC, Sillekens P, vanDeursen P, Neal KR, Irving WL. Serum HCV RNA levels assessed by quantitative $\operatorname{NASBA}(\mathrm{R})$ : stability of viral load over time, and lack of correlation with liver disease. J Hepatol 1996; 25: 01-06.

22 Chen Y. Meta-analysis: IL28B polymorphisms predict sustained viral response in HCV patients treated with pegylated interferon-a and ribavirin. Aliment Pharmacol Ther 2012; 36: 1-103.

23 Peters L, Grint D, Lundgren JD et al. Chronic Hepatitis C (HCV) Infection and Chronic Kidney Disease (CKD) in HIV-infrected Patients in the EuroSIDA Study. 13th European Aids Conference (EACS). Belgrade, Serbia, October 2011 [Abstract PS7/3].

24 Mocroft A, Neuhaus J, Peters L et al. for the INSIGHT SMART and ESPRIT Study Groups. Hepatitis B and C co-infection are independent predictors of progressive kidney disease in HIV-positive, antiretroviral-treated adults. PLoS ONE 2012; 7: e40245. 
25 Thompson AJ, Muir AJ, Sulkowski MS et al. Interleukin-28B polymorphism improves viral kinetics and is the strongest pretreatment predictor of sustained virologic response in genotype 1 hepatitis C virus. Gastroenterology 2010; 139: 20-U178.

26 Bower WA, Culver DH, Castor D et al. Changes in hepatitis C virus (HCV) viral load and interferon-alpha levels in HIV/HCV-coinfected patients treated with highly active antiretroviral therapy. Jaids J Acquir Immune Defic Syndr 2006; 42: 93-97.

27 Rutschmann OT, Negro F, Hirschel B, Hadengue A, Anwar D, Perrin LH. Impact of treatment with human immunodeficiency virus (HIV) protease inhibitors on hepatitis $C$ viremia in patients coinfected with HIV. $J$ Infect Dis 1998; 177: 83-85.

28 Chung RT, Evans SR, Yang YJ et al. Immune recovery is associated with persistent rise in hepatitis $\mathrm{C}$ virus RNA, infrequent liver test flares, and is not impaired by hepatitis C virus in co-infected subjects. Aids 2002; 16: 915-923.

29 Rohrbach J, Robinson N, Harcourt G et al. Cellular immune responses to HCV core increase and HCV RNA levels decrease during successful antiretroviral therapy. Gut 2010; 59: 252-258.

30 Cooper C. Review of the effect of highly active antiretroviral therapy on hepatitis C virus (HCV) RNA levels in human immunodeficiency virus and HCV coinfection. Clin Infect Dis 2002; 35: 73-79.

31 Konopnicki D, Mocroft A, de Wit S et al. Hepatitis B and HIV: prevalence, AIDS progression, response to highly active antiretroviral therapy and increased mortality in the EuroSIDA cohort. Aids 2005; 19: 93-601.

32 Martin-Carbonero L, Barreiro P, Jimenez-Galan G, Garcia-Berriguete R, Nunez M. Clearance of hepatitis C virus in HIV-infected patients with multiple chronic viral hepatitis.

J Viral Hepat 2007; 14: 92-95.

\section{Supporting information}

Additional Supporting Information may be found in the online version of this article at the publisher's web-site.

Appendix S1. The EuroSIDA study group. 